\title{
Current smoking status may be associated with overt albuminuria in female patients with type 1 diabetes mellitus: a cross-sectional study
}

Kenta Okada ${ }^{1 *}$, Jun-ichi Osuga ${ }^{1}$, Kazuhiko Kotani ${ }^{2}$, Hiroaki Yagyu' ${ }^{1}$ Michiaki Miyamoto', Shoichiro Nagasaka ${ }^{1}$ and Shun Ishibashi ${ }^{1}$

\begin{abstract}
Background: There are very few clinical reports that have compared the association between cigarette smoking and microangiopathy in Asian patients with type 1 diabetes mellitus (T1DM). The objective of this study was to assess the relationships between urinary protein concentrations and smoking and gender-based risk factors among patients with T1DM.

Methods: A cross-sectional study of 259 patients with T1DM (men/women =90/169; mean age, 50.7 years) who visited our hospital for more than 1 year between October 2010 and April 2011 was conducted. Participants completed a questionnaire about their smoking habits. Patient characteristics included gender, age, body mass index, blood pressure, hemoglobin A1c, lipid parameters, and microangiopathy. Diabetic nephropathy (DN) was categorized as normoalbuminuria (NA), microalbuminuria (MA), or overt albuminuria (OA) on the basis of the following urinary albumin/creatinine ratio (ACR) levels: NA, ACR levels less than $30 \mathrm{mg} / \mathrm{g}$ creatinine (Cr); MA, ACR levels between 30 and $299 \mathrm{mg} / \mathrm{g} \mathrm{Cr}$; and OA, ACR levels over $300 \mathrm{mg} / \mathrm{g} \mathrm{Cr}$.
\end{abstract}

Results: The percentages of current nonsmokers and current smokers with T1DM were $73.0 \%(n=189)$ and $27.0 \%$ ( $n=70)$, respectively. In addition, the percentage of males was higher than that of females $(52.2 \%$ versus $13.6 \%)$ in the current smoking population. The percentage of DN was $61.8 \%(n=160)$ in patients with NA, 21.6\% $(n=56)$ in patients with MA, and $16.6 \%(n=43)$ in patients with OA. The percentage of males among OA patients was also higher than that of females (24.4\% versus $12.4 \%)$. However, current smoking status was associated with OA in females with T1DM only [unadjusted odds ratio (OR), 4.13; 95\% confidence interval (Cl), 1.45-11.73, $P<0.01$; multivariate-adjusted $\mathrm{OR}, 5.41 ; 95 \% \mathrm{Cl}, 1.69-17.30, P<0.01]$.

Conclusions: Based on our results in this cross-sectional study of Asian patients with T1DM, smoking might be a risk factor for OA among female patients. Further research is needed of these gender-specific results.

Keywords: Type 1 diabetes mellitus, Current smoking, Overt albuminuria

\section{Background}

Type 1 diabetes mellitus (T1DM) is common in young people [1-3]. Because high blood glucose levels begin at a young age in T1DM, the early management of risk factors is important for preventing diabetic complications in young patients with T1DM. Overt albuminuria (OA) is a diabetic complication, and diabetic nephropathy

\footnotetext{
* Correspondence: kokada@jichi.ac.jp

${ }^{1}$ Department of Internal Medicine, Division of Endocrinology and Metabolism, Jichi Medical University, Tochigi 320-0498, Japan Full list of author information is available at the end of the article
}

(DN) is a possible predictor of renal failure and mortality in patients with T1DM $[4,5]$. The development of DN has been shown to be associated with the duration of diabetes, smoking, hemoglobin A1c (HbA1c) levels, blood pressure levels, and dyslipidemia in T1DM patients [6,7].

It has recently been reported that sex is an important factor in the prevalence of smoking and cardiovascular disease [8]. At present, only limited information is available regarding the association between $\mathrm{DN}$ and the gender-based smoking status of T1DM patients [9]. The

\section{Biomed Central}

(c) 2012 Okada et al.; licensee BioMed Central Ltd. This is an Open Access article distributed under the terms of the Creative Commons Attribution License (http://creativecommons.org/licenses/by/2.0), which permits unrestricted use, distribution, and reproduction in any medium, provided the original work is properly cited. 
EURODIAB IDDM Complications Study reported that a current smoking status is positively associated with the progression of $\mathrm{DN}$ in male and female patients with T1DM [9]. Because there have been very limited clinical studies in the Asia-Pacific regions in particular, more studies of the influence of gender on smoking habits in DN patients are required. Therefore, the present study aimed to examine risk factors, including current smoking habits that can influence the gender-based presence of OA in Japanese patients with T1DM.

\section{Subjects and methods}

A total of 259 patients with T1DM (men/women $=90 /$ 169; mean age $=50.7 \pm 16.8$ years; duration of diabetes $=17.0 \pm 11.0$ years) who visited our hospital for more than 1 year between October 2010 and April 2011 were examined. The eligibility criteria were as follows: age $>18$ years, the absence of acute ketosis, hypoglycemia, and pregnancy. T1DM was diagnosed according to the Position Statement of the American Diabetes Association [10]. T1DM was defined with the following criteria: absolute insulin deficiency (urine Cpeptide levels $<20 \mu \mathrm{g} /$ day, fasting serum C-peptide levels $<0.5 \mu \mathrm{g} / \mathrm{mL}$, or serum C-peptide levels $<1.0 \mu \mathrm{g} /$ $\mathrm{mL}$ after loading), susceptibility to ketosis, and requirement of insulin therapy within 1 year after diagnosis; all patients in this study required insulin injections. Smoking habits were confirmed by self-reports. Current smoking status was considered as either smoking or not smoking. The study protocol was approved by the Jichi Medical University Ethical Committee.

The body mass index (BMI) and systolic/diastolic blood pressure were measured in each patient. Blood and urinary samples were collected at the outpatient clinic in order to measure the levels of the following parameters: HbA1c, total cholesterol (TC), triglyceride (TG), and high-density lipoprotein cholesterol (HDL-C). A high-performance liquid chromatography (HA8131; Kyoto Daiichi Kagaku Co., Ltd., Tokyo, Japan) system was used to measure HbA1c levels according to previous Japanese standard substance and measurement methods. National Glycohemoglobin Standardization Programequivalent values were obtained by using the following equation: $\mathrm{HbA} 1 \mathrm{c}=\mathrm{HbA} 1 \mathrm{c}$ (the Japan Diabetes Society) + 0.4 [11]. TC, TG, and HDL-C levels were measured by enzymatic methods with an automatic analyzer (Hitachi Co., Ltd., Tokyo, Japan).

Urinary albumin levels were measured with the turbidimetric immunoassay method using a commercially available kit (Auto Wako Albumin; Wako Pure Chemical Industries, Ltd., Osaka, Japan), and urinary creatinine levels were determined by an enzymatic method in order to calculate the urinary albumin/creatinine ratio (ACR). $\mathrm{DN}$ was classified as normoalbuminuria (NA), microalbuminuria (MA), or OA on the basis of the following ACR levels: NA, ACR levels less than $30 \mathrm{mg} / \mathrm{g}$ creatinine (Cr); MA, ACR levels between 30 and $299 \mathrm{mg} / \mathrm{g} \mathrm{Cr}$; and OA, ACR levels over $300 \mathrm{mg} / \mathrm{g} \mathrm{Cr}$ [12]. Diabetic retinopathy and neuropathy were either present or absent.

The data are presented as mean \pm standard deviation (SD) by sex. Comparisons between the groups were made with unpaired $t$-tests and Chi-square tests. Unadjusted, age-adjusted, and multivariate-adjusted logistic regression analyses were performed in order to estimate the factors associated with urinary albuminuria. The multivariate-adjusted logistic regression analysis models included age, BMI, systolic/diastolic blood pressure, HbA1c levels, TC levels, TG levels, HDL-C levels, and current smoking status at baseline as independent variables. Statistical significance was set at $P$ values less than 0.05. All analyses were performed with the SPSS II software package (IBM Corporation, Armonk, NY).

\section{Results}

The clinical characteristics of the current smokers and nonsmokers are shown by gender in Table 1. A total of $73 \%(\mathrm{n}=189)$ of the study population were nonsmokers, while $27.0 \% \quad(n=70)$ reported themselves as current smokers. Compared to males, females constituted a significantly lower percentage of current smokers $(52.2 \%$ versus $13.6 \%, P<0.01)$. In the nonsmoking group, females had significantly higher HDL-C levels than males, while a similar but nonsignificant difference in HDL-C levels was seen in current smokers. In addition, the percentage of nonsmoking patients with OA was significantly higher in males than in females. For females, the percentage of patients with OA was significantly higher in current smokers than in nonsmokers.

The results of the unadjusted, age-adjusted, and multivariate-adjusted logistic regression analyses for OA are shown in Table 2. In males, systolic blood pressure was independently, significantly, and positively associated with OA. Diastolic blood pressure was significantly and positively associated with $\mathrm{OA}$ in the unadjusted and age-adjusted analyses, but it was no longer significantly associated with $\mathrm{OA}$ in the multivariate-adjusted logistic regression analysis. The other variables, including current smoking status, were not significantly associated with OA. In females, systolic blood pressure was also independently, significantly, and positively associated with OA. Current smoking status was found to be significantly and positively associated with $\mathrm{OA}$ in the unadjusted and age-adjusted analyses. The multivariate-adjusted logistic regression analysis revealed that current smoking status was independently, significantly, and positively associated with OA (Odds 
Table 1 Clinical characteristics

\begin{tabular}{|c|c|c|c|c|c|c|c|c|}
\hline \multirow[t]{2}{*}{ Current smoking } & \multicolumn{2}{|l|}{ Male } & \multicolumn{2}{|l|}{ Female } & \multirow[b]{2}{*}{$P_{1}$} & \multirow[b]{2}{*}{$P_{2}$} & \multirow[b]{2}{*}{$P_{3}$} & \multirow[b]{2}{*}{$P_{4}$} \\
\hline & - & + & - & + & & & & \\
\hline Total number (\%) & $43(47.8)$ & $47(52.2)$ & $146(86.4)$ & $23(13.6)$ & - & - & - & - \\
\hline Age (years) & $53.2 \pm 16.9$ & $49.4 \pm 12.6$ & $51.3 \pm 18.3$ & $45.5 \pm 12.6$ & 0.54 & 0.24 & 0.23 & 0.15 \\
\hline Body mass index $\left(\mathrm{kg} / \mathrm{m}^{2}\right)$ & $22.4 \pm 2.8$ & $22.7 \pm 3.4$ & $22.6 \pm 3.9$ & $21.8 \pm 4.1$ & 0.76 & 0.32 & 0.62 & 0.36 \\
\hline Systolic blood pressure (mmHg) & $127.4 \pm 24.0$ & $132.3 \pm 21.7$ & $125.7 \pm 18.8$ & $123.4 \pm 14.6$ & 0.62 & 0.08 & 0.31 & 0.58 \\
\hline Diastolic blood pressure (mmHg) & $70.8 \pm 11.3$ & $74.5 \pm 14.6$ & $71.2 \pm 12.4$ & $74.3 \pm 10.2$ & 0.83 & 0.94 & 0.18 & 0.26 \\
\hline $\mathrm{HbA1c}(\%)$ & $8.4 \pm 2.0$ & $8.3 \pm 1.7$ & $8.3 \pm 2.0$ & $8.7 \pm 2.2$ & 0.66 & 0.34 & 0.73 & 0.30 \\
\hline Total cholesterol (mg/dL) & $189.7 \pm 32.1$ & $187.5 \pm 41.4$ & $199.1 \pm 37.5$ & $197.3 \pm 35.9$ & 0.14 & 0.34 & 0.78 & 0.84 \\
\hline Triglyceride (mg/dL) & $96.9 \pm 60.2$ & $116.2 \pm 81.9$ & $94.7 \pm 91.3$ & $98.0 \pm 58.5$ & 0.88 & 0.34 & 0.21 & 0.87 \\
\hline HDL-cholesterol (mg/dL) & $68.2 \pm 18.1$ & $67.2 \pm 22.1$ & $75.9 \pm 19.1$ & $74.3 \pm 13.2$ & 0.02 & 0.16 & 0.82 & 0.70 \\
\hline \multicolumn{9}{|l|}{ Complication, n (\%) } \\
\hline Retinopathy & $24(55.8)$ & $26(55.3)$ & $64(43.8)$ & $11(47.8)$ & 0.17 & 0.56 & 0.96 & 0.72 \\
\hline Neuropathy & $28(65.1)$ & $28(59.6)$ & $86(58.9)$ & $15(65.2)$ & 0.46 & 0.65 & 0.59 & 0.57 \\
\hline \multicolumn{9}{|l|}{ Nephropathy } \\
\hline Normoalbuminuria & $25(58.1)$ & $25(53.2)$ & $96(65.8)$ & $14(60.9)$ & 0.36 & 0.54 & 0.64 & 0.65 \\
\hline Microalbuminuria & $9(20.9)$ & $9(19.1)$ & $36(24.7)$ & $2(8.7)$ & 0.61 & 0.26 & 0.83 & 0.09 \\
\hline Overt albuminuria & $9(20.9)$ & $13(27.7)$ & $14(9.6)$ & $7(30.4)$ & 0.04 & 0.81 & 0.46 & $<0.01$ \\
\hline
\end{tabular}

Data are presented as the number or mean \pm S.D. HbA1c: hemoglobin A1c. HDL: high-density lipoprotein. $P_{1}$ : comparisons of respective variables between genders in nonsmokers, $P_{2}$ : comparisons of respective variables between genders in current smokers, $P_{3}$ : comparisons of respective variables between nonsmokers and current smokers in males, $P_{4}$ : comparisons of respective variables between nonsmokers and current smokers in females (using unpaired $t$-tests and Chi-square tests).

Ratio, 5.41; 95\% Confidence Interval, 1.69-17.30; $P<0.01)$.

\section{Discussion}

In the present study, the female T1DM group had a lower prevalence of $\mathrm{OA}$ than the male T1DM group. Furthermore, current smoking status was significantly associated with urinary OA in female T1DM patients, while no factor was significantly associated with $\mathrm{OA}$ in male T1DM patients. It is well known that the avoidance of smoking has beneficial health effects in patients with diabetes $[13,14]$. Furthermore, the proportion of smokers in our country has been gradually decreasing as the prevalence of smoking in patients with diabetes was

Table 2 Logistic regression analysis for urinary protein ( $\geq 300 \mathrm{mg} / \mathrm{g}$ creatinine)

\begin{tabular}{|c|c|c|c|c|c|c|c|c|c|c|c|c|}
\hline & \multicolumn{6}{|l|}{ Male $(n=90)$} & \multicolumn{6}{|l|}{ Female $(n=169)$} \\
\hline & \multicolumn{2}{|l|}{ Unadjusted } & \multicolumn{2}{|l|}{ Age-adjusted } & \multicolumn{2}{|l|}{ Multi-adjusted } & \multicolumn{2}{|l|}{ Unadjusted } & \multicolumn{2}{|l|}{ Age-adjusted } & \multicolumn{2}{|l|}{ Multi-adjusted } \\
\hline & OR $(95 \% \mathrm{Cl})$ & $P$ & OR $(95 \% \mathrm{CI})$ & $P$ & OR $(95 \% \mathrm{Cl})$ & $P$ & OR $(95 \% \mathrm{Cl})$ & $P$ & OR $(95 \% \mathrm{Cl})$ & $P$ & OR $(95 \% \mathrm{Cl})$ & $P$ \\
\hline Age (years) & $1.00(0.97-1.04)$ & 0.81 & & & $1.00(0.96-1.04)$ & 0.85 & $0.99(0.97-1.02)$ & 0.48 & & & $0.96(0.92-1.00)$ & 0.07 \\
\hline BMI $\left(\mathrm{kg} / \mathrm{m}^{2}\right)$ & $1.10(0.94-1.28)$ & 0.23 & $31.10(0.94-1.28)$ & 0.22 & $21.04(0.84-1.23)$ & 0.72 & $0.97(0.85-1.10)$ & 0.59 & $90.97(0.86-1.10)$ & 0.62 & $20.96(0.83-1.10)$ & 0.52 \\
\hline $\mathrm{SBP}(\mathrm{mmHg})$ & $1.03(1.01-1.06)<$ & 0.01 & $1.03(1.01-1.06)$ & $<0.01$ & $1.04(1.00-1.08)$ & 0.03 & $1.03(1.01-1.06)$ & 0.02 & $21.05(1.01-1.08)$ & $<0.01$ & $11.06(1.02-1.11)$ & 0.01 \\
\hline $\mathrm{DBP}(\mathrm{mmHg})$ & 1.04 (1.00-1.08) & 0.04 & $41.04(1.00-1.08)$ & 0.04 & 40.99 (0.94-1.05) & 0.78 & $1.03(0.99-1.07)$ & 0.18 & 81.03 (0.99-1.07) & 0.21 & $10.98(0.93-1.03)$ & 0.44 \\
\hline HbA1c (\%) & $0.99(0.76-1.29)$ & 0.95 & $0.99(0.77-1.29)$ & 0.96 & $61.05(0.76-1.46)$ & 0.78 & $1.03(0.83-1.27)$ & 0.81 & $11.01(0.82-1.26)$ & 0.90 & $01.04(0.77-1.39)$ & 0.81 \\
\hline $\mathrm{TC}(\mathrm{mg} / \mathrm{dL})$ & $1.01(0.99-1.03)$ & 0.09 & $1.01(0.99-1.03)$ & 0.09 & $91.01(0.99-1.03)$ & 0.21 & $1.00(0.98-1.01)$ & 0.57 & 70.99 (0.98-1.01) & 0.54 & 40.99 (0.97-1.01) & 0.26 \\
\hline $\begin{array}{l}\text { Triglyceride } \\
\text { (mg/dL) }\end{array}$ & $1.00(0.99-1.01)$ & 0.42 & $21.00(0.99-1.01)$ & 0.39 & $91.00(0.99-1.01)$ & 0.61 & $1.00(0.99-1.01)$ & 0.84 & $41.00(0.99-1.01)$ & 0.76 & $61.00(0.99-1.01)$ & 0.87 \\
\hline $\begin{array}{l}\mathrm{HDL}-\mathrm{C} \\
(\mathrm{mg} / \mathrm{dL})\end{array}$ & 1.01 (0.99-1.03) & 0.46 & $51.01(0.99-1.03)$ & 0.48 & $80.99(0.95-1.02)$ & 0.44 & $1.00(0.97-1.02)$ & 0.80 & $1.00(0.97-1.02)$ & 0.80 & $01.02(0.98-1.06)$ & 0.37 \\
\hline $\begin{array}{l}\text { Current } \\
\text { smoking }\end{array}$ & $1.44(0.55-3.83)$ & 0.46 & $51.48(0.55-3.97)$ & 0.44 & $41.15(0.37-3.50)$ & 0.81 & $4.13(1.45-11.73)$ & $<0.01$ & $14.00(1.40-11.47)$ & 0.01 & $15.41(1.69-17.30)$ & $<0.01$ \\
\hline
\end{tabular}

OR: odds ratio. Cl: confidence interval. BMI: body mass index. SBP: systolic blood pressure. DBP: diastolic blood pressure. HbA1c: hemoglobin A1c. TC: Total cholesterol. HDL-C: high-density lipoprotein-cholesterol. Multivariate-adjusted analysis models include age, BMI, SBP, DBP, HbA1C, TC, triglyceride, HDL-C, and current smoking status. 
high, especially in young female T1DM patients [15]. Based on these results, we propose that female patients with T1DM should cease smoking in order to prevent DN.

Smoking increases the concentration of carboxyhemoglobin, platelet aggregability, and the fibrinogen concentration, all of which cause tissue hypoxia and contribute to vascular damage $[16,17]$, especially that caused by diabetes [18]. Glomerular hyperfiltration [19], the suppression of water excretion [20], and the effects of proximal tubular damage [21] from smoking are the mediators of DN progression.

In this study, we found a relatively stronger correlation between smoking and $\mathrm{DN}$ in females than in males. However, the underlying mechanisms for this remain unclear. Smoking can decrease the atheroprotective effects of estrogens [22,23]. Smoking appears to alter estradiol metabolism, leading to the increased production of inactive catechols [23]. This may be related to the induction of estrogen-metabolizing cytochrome P450 isoenzymes [24]; furthermore, smoking lowers estrogen activity $[25,26]$. The effects of estrogen dysfunction on DN progression might be greater than the effects of a lowered amount of estrogen (probably corresponding to male patients). The oxidative milieu can result in proinflammatory effects of HDL $[27,28]$. In this study, HDL-C levels in female patients were high relative to male patients (particularly in nonsmokers); however, instead of affecting the actual HDL-C levels, diabetic states might make HDL dysfunctional. Functional studies to verify these hypotheses are warranted.

Females were more likely to be assigned to a lowerrisk category than males, even though the former are at an equivalent calculated risk [8]. Probably, a higher proportion of females compared to males develop DN from T1DM because of a lack of awareness and a systematic delay in the diagnosis of complications. In Japan, a small percentage of female individuals exhibit smoking habits [15]; hence, this situation is less alarming for female patients compared to male patients.

This study had a limitation related to the interpretation of data that warrants mention. First, the sample size of the groups may have been too small to produce definite conclusions. Moreover, it is necessary to consider that this study was a cross-sectional study and was only conducted at a single center. This study was performed in a local university hospital, which might not be representative of the entire T1DM population in Japan. One possibility is that T1DM patients who had undergone kidney dialysis, especially males, would discontinue visiting our hospital. Moreover, patients would visit our hospital when the complications associated with diabetes had become severe and progressive, as mentioned in a previous report [29]. Therefore, a multicenter study with a large number of patients is required. Second, because the dose of smoking [5,30], the duration of smoking, and the type of cigarette [31] were significantly associated with the progression of nephropathy, we might have to investigate these factors in detail. In addition, the self-reporting of smoking habits can be questionable because of underreporting.

\section{Conclusions}

In conclusion, the present study suggested that current smoking status can promote renal dysfunction in female T1DM patients, and we may need to take into account an individual's smoking status in the management of T1DM, especially in females.

\section{Abbreviations}

T1DM: Type 1 diabetes mellitus; DN: Diabetic nephropathy; NA: Normoalbuminuria; MA: Microalbuminuria; OA: Overt albuminuria; ACR: Albumin/creatinine ratio; $\mathrm{Cr}$ : Creatinine; HbA1c: Hemoglobin A1c; BMI: Body mass index; TC: Total cholesterol; TG: Triglyceride; HDL-C: Highdensity lipoprotein cholesterol; SD: Standard deviation.

\section{Competing interests}

The authors declare that they have no competing interests.

\section{Authors' contributions}

$\mathrm{KO}$ researched the data, wrote the manuscript and contributed to the discussion; KK analyzed the data and edited and reviewed the manuscript; MM provided the data; HY, JO, and SN contributed to the discussion; and SI contributed to the discussion and reviewed the manuscript. All authors read and approved the final manuscript.

\section{Acknowledgment}

No funding has been received. The authors thank the staff in our hospital.

\section{Author details}

${ }^{1}$ Department of Internal Medicine, Division of Endocrinology and

Metabolism, Jichi Medical University, Tochigi 320-0498, Japan. Department of Clinical Laboratory Medicine, Jichi Medical University, Tochigi 320-0498, Japan.

Received: 29 February 2012 Accepted: 6 August 2012 Published: 10 August 2012

\section{References}

1. Karvonen M, Viik-Kajander M, Moltchanova E, Libman I, LaPorte R, Tuomilehto J: Incidence of childhood type 1 diabetes worldwide. Diabetes Mondiale (DiaMond) Project Group. Diabetes Care 2000, 23:1516-1526.

2. EURODIAB ACE Study Group: Variation and trends in incidence of childhood diabetes in Europe. Lancet 2000, 355:873-876.

3. Japan IDDM Epidemiology Study Group: Lack of regional variation in IDDM risk in Japan. Diabetes Care 1993, 16:796-800.

4. Chase HP, Garg SK, Marshall G, Berg CL, Harris S, Jackson WE, Hamman RE: Cigarette smoking increases the risk of albuminuria among subjects with type 1 diabetes. JAMA 1991, 265:614-617.

5. Sawicki PT, Didjurgeit U, Mühlhauser I, Bender R, Heinemann L, Berger M: Smoking is associated with progression of diabetic nephropathy. Diabetes Care 1994, 17:126-131.

6. Raile K, Galler A, Hofer S, Herbst A, Dunstheimer D, Busch P, Holl RW: Diabetic nephropathy in 27,805 children, adolescents, and adults with type 1 diabetes: effect of diabetes duration, A1C, hypertension, dyslipidemia, diabetes onset, and sex. Diabetes Care 2007, 30:2523-2528.

7. Scott LJ, Warram JH, Hanna LS, Laffel LM, Ryan L, Krolewski AS: A nonlinear effect of hyperglycemia and current cigarette smoking are major determinants of the onset of microalbuminuria in type 1 diabetes. Diabetes 2001, 50:2842-2849.

8. Mosca L, Linfante AH, Benjamin EJ, Berra K, Hayes SN, Walsh BW, Fabunmi RP, Kwan J, Mills T, Simpson SL: National study of physician awareness 
and adherence to cardiovascular disease prevention guidelines. Circulation 2005, 111:499-510.

9. Chaturvedi N, Stephenson JM, Fuller JH: The relationship between smoking and microvascular complications in the EURODIAB IDDM Complications Study. Diabetes Care 1995, 18:785-792.

10. American Diabetes Association: Diagnosis and classification of diabetes mellitus. Diabetes Care 2010, 33:S62-S69.

11. Seino Y, Nanjo K, Tajima N, Kadowaki T, Kashiwagi A, Araki E, Ito C, Inagaki N, Iwamoto Y, Kasuga M, Hanafusa T, Haneda M, Ueki K: Report of the committee on the classification and diagnostic criteria of diabetes mellitus. Diabetol Int 2010, 1:2-20.

12. Hirano T, Sakaue T, Misaki A, Murayama S, Takahashi T, Okada K, Takeuchi H, Yoshino G, Adachi M: Very low-density lipoprotein-apoprotein Cl is increased in diabetic nephropathy: comparison with apoprotein CIII. Kidney Int 2003, 63:2171-2177.

13. Resnick HE, Foster GL, Bardsley J, Ratner RE: Achievement of American Diabetes Association clinical practice recommendations among U.S. adults with diabetes, 1999-2002: the National Health and Nutrition Examination Survey. Diabetes Care 2006, 29:531-537.

14. Haire-Joshu D, Glasgow RE, Tibbs TL: American Diabetes Association: Smoking and diabetes. Diabetes Care 2004, 27:S74-S75.

15. Nilsson PM, Gudbjörnsdottir S, Eliasson B, Cederholm J: Steering Committee of the Swedish National Diabetes Register: Smoking is associated with increased $\mathrm{HbA1c}$ values and microalbuminuria in patients with diabetes-data from the National Diabetes Register in Sweden. Diabetes Metab 2004, 30:261-268.

16. Orth SR, Ritz E, Schrier RW: The renal risks of smoking. Kidney Int 1997, 51:1669-1677.

17. Nilsson TK, Lithner F: Glycaemic control, smoking habits and diabetes duration affect the extrinsic fibrinolytic system in type I diabetic patients but microangiopathy does not. Acta Med Scand 1988, 224:123-129.

18. Mühlhauser I: Smoking and diabetes. Diabet Med 1990, 7:10-15.

19. Ekberg G, Grefberg N, Larsson LO, Vaara I: Cigarette smoking and glomerular filtration rate in insulin-treated diabetics without manifest nephropathy. J Intern Med 1990, 228:211-217.

20. Cadnapaphornchai P, Boykin JL, Berl T, McDonald KM, Schrier RW: Mechanism of effect of nicotine on renal water excretion. Am J Physiol 1974, 227:1216-1220.

21. Hultberg B, Isaksson A, Brattström L, Israelsson B: Elevated urinary excretion of beta-hexosaminidase in smokers. Eur I Clin Chem Clin Biochem 1992, 30:131-133.

22. Baron JA, La Vecchia C, Levi F: The antiestrogenic effect of cigarette smoking in women. Am J Obstet Gynecol 1990, 162:502-514.

23. MacMahon B, Trichopoulos D, Cole P, Brown J: Cigarette smoking and urinary estrogens. N Engl J Med 1982, 307:1062-1065.

24. Meek MD, Finch GL: Diluted mainstream cigarette smoke condensates activate estrogen receptor and aryl hydrocarbon receptor-mediated gene transcription. Environ Res 1999, 80:9-17.

25. Tankó LB, Christiansen C: An update on the antiestrogenic effect of smoking: a literature review with implications for researchers and practitioners. Menopause 2004, 11:104-109.

26. Michnovicz JJ, Hershcopf RJ, Naganuma H, Bradlow HL, Fishman J: Increased 2-hydroxylation of estradiol as a possible mechanism for the antiestrogenic effect of cigarette smoking. N Engl J Med 1986, 315:1305-1309.

27. Navab M, Reddy S, Van Lenten BJ, Anantharamaiah GM, Fogelman AM: Role of dysfunctional HDL in atherosclerosis. J Lipid Res 2009, 50:S145-S149.

28. Vaziri ND, Navab M, Fogelman AM: HDL metabolism and activity in chronic kidney disease. Nat Rev Nephrol 2010, 6:287-296.

29. Yokoyama H, Okudaira M, Otani T, Takaike H, Miura J, Saeki A, Uchigata Y, Omori Y: Existence of early-onset NIDDM Japanese demonstrating severe diabetic complications. Diabetes Care 1997, 20:844-847.

30. Parving $\mathrm{HH}$ : Diabetic nephropathy: prevention and treatment. Kidney Int 2001, 60:2041-2055.

31. Rossing $\mathrm{P}$, Hougaard $\mathrm{P}$, Parving $\mathrm{HH}$ : Risk factors for development of incipient and overt diabetic nephropathy in type 1 diabetic patients: a 10-year prospective observational study. Diabetes Care 2002, 25:859-864.

\section{Submit your next manuscript to BioMed Central and take full advantage of:}

- Convenient online submission

- Thorough peer review

- No space constraints or color figure charges

- Immediate publication on acceptance

- Inclusion in PubMed, CAS, Scopus and Google Scholar

- Research which is freely available for redistribution 